\title{
A Study of Along Wind Speed Power Spectrum for Taiwan Area
}

Jing-Jong Jang

Associate Professor, Department of Harbor and River Engineering. National Taiwan Ocean Universiry, Keelung, Taiwan 20224. R.O.C.

Yu-Lin Lee

Graduate Student, Deparment of Harbor and River Engineering. National Taiwan Ocean Universiry, Keelung. Taiwan 20224, R.O.C.

Follow this and additional works at: https://jmstt.ntou.edu.tw/journal

Part of the Civil and Environmental Engineering Commons

\section{Recommended Citation}

Jang, Jing-Jong and Lee, Yu-Lin (1998) "A Study of Along Wind Speed Power Spectrum for Taiwan Area," Journal of Marine Science and Technology: Vol. 6: Iss. 1, Article 9.

DOI: $10.51400 / 2709-6998.2522$

Available at: https://jmstt.ntou.edu.tw/journal/vol6/iss1/9

This Research Article is brought to you for free and open access by Journal of Marine Science and Technology. It has been accepted for inclusion in Journal of Marine Science and Technology by an authorized editor of Journal of Marine Science and Technology. 


\section{A Study of Along Wind Speed Power Spectrum for Taiwan Area}

\section{Acknowledgements}

The authors would like to thank the National Science Council for funding this research (Project No. NSC85-2611-E-019-037). 


\title{
A STUDY OF ALONG WIND SPEED POWER SPECTRUM FOR TAIWAN AREA
}

\author{
Jing-Jong Jang* and Yu-Lin Lee**
}

Keywords: Along wind, Spectrum, Taiwan area, Structural design.

\begin{abstract}
The Purpose of this paper is to formulate the wind speed power spectrum by time history data of strong wind speed in Taiwan area. By utilizing random vibration theory and statistical regression analysis, a systematic analysis and discussions of along wind turbulence effects for wind speed power spectrum is performed. This study includes the time history data collection of along wind speed for typhoon in Taiwan and the regression analysis of wind speed spectral formulas. The strong wind speed data was first transformed from time domain to frequency domain. Then, the statistical analysis methods were applied for spectrum formulation and regression analysis. At the end of this study, a suitable along wind speed power spectral formula for future wind-resistant structural design for Taiwan area is presented.
\end{abstract}

\section{INTRODUCTION}

The portion of the tall and huge structures above ground or sea level is usually sensitive to strong wind force. In practice, wind force is one of the most important loading factors for structural design in addition to earthquake force. The response of structures when subjected to dynamic wind force is very complicate. Usually, the dynamic wind effect is much larger than the static one, and their ratio is called the dynamic gust wind factor. If a structure is designed by the current wind loading design code which is based on static analysis, it will be neither safe nor economical. The dynamic effects of wind pressure force on tall and slender structures should be considered carefully to ensure the structural safety.

The wind speed changes from time to time. Because of its nature of uncertainty, the statistical

Paper Received January, 1998. Revised April, 1998. Accepted May. 1998. Author for Correspondence: Jing-Jong Jang.

*Associate Professor, Department of Harbor and River Engineering, National Taiwan Ocean University, Keelung, Taiwan 20224, R.O.C.

**Graduate Student, Department of Harbor and River Engineering.

National Taiwan Ocean University, Keelung, Taiwan 20224, R.O.C. methods, such as mean, standard deviation and probability density function are required for description and evaluation. Generally, for the convenience of analysis, it is assumed that the mean of the whole wind speed data batch obtained at any designated time $t_{i}$ will not change despite of the variation of time $t_{i}$. Therefore, the wind speed is considered as a stationary random process for spectrum analysis in this paper.

\section{ESTABLISHMENT OF WIND SPEED POWER SPECTRUM}

Davenport [1] suggested that fluctuation wind speed may be expressed by Fourier series as follows:

$$
u(Z, t)=\sum_{j=1}^{\infty} u_{j} \sin \left(2 \pi \frac{j}{T_{o}} t+\phi_{j}\right),
$$

where $Z=$ the elevation,

$\frac{j}{T_{o}}=$ the jth harmonic frequency,
$u_{j}=$ the jth amplitude,
$\phi_{j}=$ the jth phase angle,

The mean square root can be formulated as follows:

$$
\begin{aligned}
& \bar{u}^{2}=\sum_{j=1}^{\infty} \frac{u_{j}^{2}}{2}, \\
& \text { or } \quad \bar{u}^{2}=\int_{0}^{\infty} \frac{u^{2}(Z, n)}{2} d n, \\
& \text { where } n=\frac{j}{T_{o}}=\text { frequency. }
\end{aligned}
$$

In Eq. (2), $\frac{u^{2}(Z, n)}{2}$ is defined as $S_{u}(Z, n)$ which indicates the energy spectral density function for vertical turbulence fluctuation $u(Z, t)$.

\section{Auto-Correlation Spectrum}

Based on stationary random function $u(Z, t)$, Auto-correlation function $R_{u u}(\tau)$ is defined as follows to describe the correlation relationship among various 
time periods in the same batch record:

$$
\begin{aligned}
& R_{u u}(\tau)=E[u(t) u(t+\tau)], \\
& =\lim _{T \rightarrow \infty}\left[\frac{1}{T} \int_{0}^{T} u(Z, t) u(Z, t+\tau) d t\right] .
\end{aligned}
$$

According to the assumption that this process is stationary and random, $R_{u u}(\tau)$ is only related to delayed time $\tau$, but not to absolute time $t$. The formula is as follows:

$$
\begin{aligned}
R_{u u}(\tau) & =E[u(\mathrm{t}) u(t+\tau)], \\
& =E[u(t) u(t-\tau)], \\
& =R_{u u}(-\tau) .
\end{aligned}
$$

The implication of Eq. (4), $R_{u u}(\tau)$ is an even function. Assume that:

$$
R_{u u}(\tau \rightarrow \infty)=0 \text { and } \int_{-\infty}^{\infty}\left|R_{u u}(\tau)\right| d t<\infty .
$$

The energy spectral density function then can be obtained by proceeding $R_{u u}(\tau)$ with Fourier conversion,

$$
S_{u u}(n)=\int_{-\infty}^{\infty} R_{u u}(\tau) e^{-i 2 n \pi \tau} d \tau .
$$

Equation (5) is the vertical turbulence frequency spectrum density function when $u$ is specified by wind speed.

\section{Cross-Correlation Spectrum}

Assume that stationary random process $U(t)$ is overlapped by two independent stationary random processes each with a mean of zero. The auto-correlation function $U(t)\left(u_{1}(t)+u_{2}(t)\right)$ of $R_{U U}(\tau)$ then is defined as following:

$$
\begin{aligned}
R_{U U}(\tau) & =E[U(t) U(t+\tau)], \\
& =E\left[\left\{u_{1}(t)+u_{2}(t)\right\}\left\{u_{1}(\mathrm{t}+\mathrm{t})+u_{2}(t+\tau)\right\}\right], \\
& =E\left[u_{1}(\mathrm{t}) u_{1}(t+\tau)\right]+E\left[u_{1}(\mathrm{t}) u_{2}(t+\tau)\right], \\
& +E\left[u_{2}(\mathrm{t}) u_{1}(t+\tau)\right]+E\left[u_{2}(\mathrm{t}) u_{2}(t+\tau)\right], \\
& =R_{u_{1} u_{1}}(\tau)+R_{u_{1} u_{2}}(\tau)+R_{u u_{1} u_{1}}(\tau)+R_{u_{2} u_{2}}(\tau) .
\end{aligned}
$$

While $R_{u_{1} u_{1}}(\tau)$ and $R_{u_{2} u_{2}}(\tau)$ in Eq. (6) are auto-correlation functions as defined in Eq. (3), $R_{u_{1} u_{2}}(\tau)$ and $R_{u 2 u 1}(\tau)$ which indicate below are related to each other as cross-correlation functions:

$$
\left\{\begin{array}{l}
R_{u_{1} u_{2}}(\tau)=\lim _{T \rightarrow \infty}\left[\frac{1}{T} \int_{0}^{T} u_{1}(Z, t) u_{2}(Z, t+\tau) d t\right], \\
R_{u_{2} u_{1}}(\tau)=\lim _{T \rightarrow \infty}\left[\frac{1}{T} \int_{0}^{T} u_{2}(Z, t) u_{1}(Z, t+\tau) d t\right] .
\end{array}\right.
$$

Because the two equations are stationary random processes, then we have

$$
\left\{\begin{array}{l}
R_{u_{1} u_{2}}(\tau)=R_{u_{u u_{1}}}(-\tau), \\
R_{u_{2^{u_{1}}}}(\tau)=R_{u_{1} u_{2}}(-\tau) .
\end{array}\right.
$$

The co-spectrum $S_{u_{1} u_{2}}^{c}(n)$ and quadature spectrum $S_{u_{1} u_{2}}^{q}(n)$ are defined as follows:

$$
\begin{aligned}
& S_{u_{1} u_{2}}^{c}(n)=2 \int_{-\infty}^{\infty} R_{u_{1} u_{2}}(\tau) \cos (2 n \pi \tau) d \tau, \\
& S_{u_{1} u_{2}}^{q}(n)=2 \int_{-\infty}^{\infty} R_{u_{1} u_{2}}(\tau) \sin (2 n \pi \tau) d \tau .
\end{aligned}
$$

By applying Eq. (8), one can get

$$
\left\{\begin{array}{l}
S_{u_{1} u_{2}}^{c}(n)=S_{u_{2} u_{1}}^{c}(n), \\
S_{u_{1} u_{2}}^{q}(n)=-S_{u_{2} u_{1}}^{q}(n) .
\end{array}\right.
$$

Assume that two different location data are sampled from point $M_{1}$ and point $M_{2}$ with vertical distance $r$ in between. The cross-spectrum of vertical turbulence fluctuation is defined as follows:

$$
S_{u_{1} u_{2}}(r, n)=S_{u_{1} u_{2}}^{c}(r, n)+i S_{u_{1} u_{2}}^{q}(r, n) .
$$

Under dimensionless analysis, coherence function $\vartheta(r, n)$ is defined as

$$
\vartheta(r, n)=\operatorname{Coh}^{2}(r, n)=c_{u_{1} u_{2}}^{2}+q_{u_{1} u_{2}}^{2}(r, n),
$$

where $c_{u_{1} u_{2}}^{2}(r, n)=\frac{\left[S_{u_{1} u_{2}}^{c}(r, n)\right]^{2}}{S_{u_{1}}\left(Z_{1}, n\right) S_{u_{2}}\left(Z_{2}, n\right)}$,

$$
q_{u_{1} u_{2}}^{2}(r, n)=\frac{\left[S_{u_{1} u_{2}}^{q}(r, n)\right]^{2}}{S_{u_{1}}\left(Z_{1}, n\right) S_{u_{2}}\left(Z_{2}, n\right)} .
$$

$S_{u_{1}}\left(Z_{1}, n\right)$ and $S_{u 2}\left(Z_{2}, n\right)$ represent the vertical turbulence fluctuation spectrum between point $M_{1}$ and $M_{2}$.

Davenport [2] assumed that the line connecting point $M_{1}$ and $M_{2}$ is perpendicular to the along wind speed direction, and suggested that the coherence function or so called narrow-band cross-correlation is defined as following:

$$
\operatorname{Coh}(r, n)=e^{-\hat{f}},
$$


where $\hat{f}=\frac{n\left[C_{Z}^{2}\left(Z_{1}-Z_{2}\right)^{2}+C_{Y}^{2}\left(Y_{1}-Y_{2}\right)^{2}\right]^{1 / 2}}{\frac{1}{2}\left[U\left(Z_{1}\right)+\left(Z_{2}\right)\right]}$.

$Y_{1}$ and $Y_{2}$ are horizontal coordinates of $M_{1}$ and $M_{2}$, while $Z_{1}$ and $Z_{2}$ are vertical ones. $C_{Y}$ and $C_{Z}$ which indicate exponential decay coefficients are related to ground surface roughness, altitude, and wind speed. Usually $C_{Y}=16$ and $C_{Z}=10$ are used [3].

\section{FORMULATIONS OF WIND SPEED POWER SPECTRUM}

Since the purpose of this study is to find out a suitable formula of along wind speed spectrum for Taiwan area, the following formulas from literature which only focus on along wind speed turbulence spectrum may be used for regression analysis.

1. Kolmogorov [4]:

$$
\frac{n S_{u}(Z, n)}{u_{*}^{2}}=0.26 f^{-2 / 3},
$$

where $n=$ Frequency (unit: Hertz),

$u^{*}=$ friction velocity,

$f=\frac{n Z}{U(Z)}=$ reduced frequency which is a non-factor measurement,

$U(Z)=$ the mean wind speed at height $Z$.

According to the spectrum study of Solari [3], the higher frequency area of Eq. (18) will get the better results.

2. Von Karman [5]:

$$
\frac{n S_{u}(Z, n)}{\tilde{u}^{2}}=\frac{4\left(\frac{n L_{u}^{x}}{U}\right)}{\left[1+70.8\left(\frac{n L_{u}^{x}}{U}\right)^{25 / 6}\right.},
$$

where $L_{u}^{x}=151\left(\frac{Z}{10}\right)^{\alpha} L=$ integral length scale (unit: meter),

$\alpha_{L}=$ Coefficient as indication of relationship with altitude.

Although this spectra is not good for those highfrequency structures, it can be applied on those structures with low-frequency, such as ocean platform with long period.

\section{Davenport [1]:}

$$
\frac{n S_{u}(n)}{u_{*}^{2}}=\frac{4.0 x^{2}}{\left(1+x^{2}\right)^{4 / 3}},
$$

where $x=\frac{1200 n}{U(10)}$,
$U(10)=$ the mean wind speed of $10 \mathrm{~m}$ altitude.

This formula has been adopted by SNBCC (Supplement to the National Building Code of Canada, 1990) and ANSI (American National Standards Institute, 1990). It is noted that this spectra has no relationship with altitude. Simiu [4] indicates that when the altitude is 300 meters and the ground surface roughness length is $0.08 \mathrm{~m}$, this formulas will result $100 \%$ to $400 \%$ of over-estimation if high-frequency $(n>0.1)$ spectral area is used.

4. Harris [6] ("Von Karman" type spectrum):

$$
\frac{n S_{u}(n)}{u_{*}^{2}}=\frac{4.0 x^{2}}{\left(2+x^{2}\right)^{5 / 6}},
$$

where $x=\frac{1800 n}{U(10)}$.

This spectra has been adopted by ESDU (Engineering Science Data Unit, 1989). The functional form is similar to Eq. (20) and is not a function of altitude either.

5. Hino [7](“Von Karman" type spectrum):

$$
\frac{n S_{u}(Z, n)}{\bar{u}^{2}}=\frac{0.475 x}{\left(1+x^{2}\right)^{5 / 6}}
$$

where $x=\frac{250 n Z^{0.42}}{U(Z)}$.

6. Kaimal [8] \& Simiu [9]:

$$
\frac{n S_{u}(Z, n)}{u_{*}^{2}}=\frac{200 f}{(1+50 f)^{5 / 3}},
$$

where $f=\frac{n Z}{U(Z)}$.

This spectra has been adopted by NBS (National Bureau of Standards, 1980). It can be applied to both low-frequency and high-frequency spectrum area.

7. Reinhold, et al. [4]:

$$
\frac{n S_{u}(Z, n)}{\bar{u}^{2}}=\frac{4\left(n L_{u}^{x} / U\right)}{\left[1.0+71.05\left(n L_{u}^{x} / U\right)^{2}\right]^{5 / 6}} .
$$

8. Simiu [9]:

$$
\frac{n S_{u}(Z, n)}{u_{*}^{2}}= \begin{cases}c_{1}+a_{1} f+b_{1} f^{2}, & 0 \leq f \leq f_{m}, \\ c_{2}+a_{2} f+b_{2} f^{2}, & f_{m} \leq f \leq f_{s} .\end{cases}
$$

where $f_{m}=$ Peak similarity coordinate,

$f_{s}=$ Lower limit of inertial subrange.

9. Teunissen [10]: 


$$
\frac{n S_{u}(Z, n)}{u_{*}^{2}}=\frac{105 f}{(0.44+33 f)^{5 / 3}} .
$$

10. Olesen, et al. [11]:

$$
\frac{n S_{u}(Z, n)}{u_{*}^{2}}=\frac{A f^{\gamma}}{\left(1+B f^{\hat{\alpha}}\right)^{\beta}},
$$

where $f_{m}=\left(\frac{1.5 \gamma}{B}\right)^{1 / \alpha}$, and $\gamma-\hat{\alpha} \beta=-2 / 3$.

The values of $A, B, \hat{\alpha}, \beta, \gamma$ will change from highfrequency to low-frequency range. The constants $A$ and $B$ determine the spectral frequency range, while parameters $\hat{\alpha}, \beta, \gamma$ determine the spectral shape.

\section{Solari [12]:}

$$
\frac{n S_{u}(Z, n)}{u_{*}^{2}}=\frac{2.21 \beta^{2.5} f}{\left(1+3.31 \beta^{1.5} f\right)^{5 / 3}},
$$

where $\sigma_{u}^{2}(Z)=\beta u_{*}^{2}, \beta=5.53$,

$$
\sigma_{u}=\text { standard deviation of } u \text {. }
$$

\section{Solari [13]:}

$$
\frac{n S_{u}(Z, n)}{\bar{u}^{2}}=\frac{6.868\left(\frac{f L_{u}}{Z}\right)}{\left[1+10.302\left(\frac{f L_{u}}{Z}\right)\right]^{5 / 3}},
$$

when $f_{m}=0.1456 \frac{Z}{L_{u}(Z)}, n S_{u}(Z, n)$ will reaches maximum value.

The above turbulence spectral density formulas have their own advantages and disadvantages. Up to today, most countries has their own wind speed turbulence spectrum. However, there is not any wind speed spectral formula proposed or established for Taiwan area until now. Therefore, this research would like to synthesize and recommend an along wind speed spectra for Taiwan area, and hope that will be helpful for future structural wind resistant design and building codes modification.

\section{REGRESSION OF ALONG WIND SPEED POWER SPECTRUM FOR TAIWAN AREA}

The wind speed data collected by the Central Weather Bureau of Taiwan is only available for average or maximum wind speed. For those continuous time history wind speed data with frequency greater than $5 \mathrm{~Hz}$, the Central Weather Bureau does not have further collection. Owing to such a limitation, the wind speed data used in this study for along wind speed turbulence spectrum analysis is based on two sources: 1) strong wind speed data from the anemometer collected by the authors, and 2) continuous wind

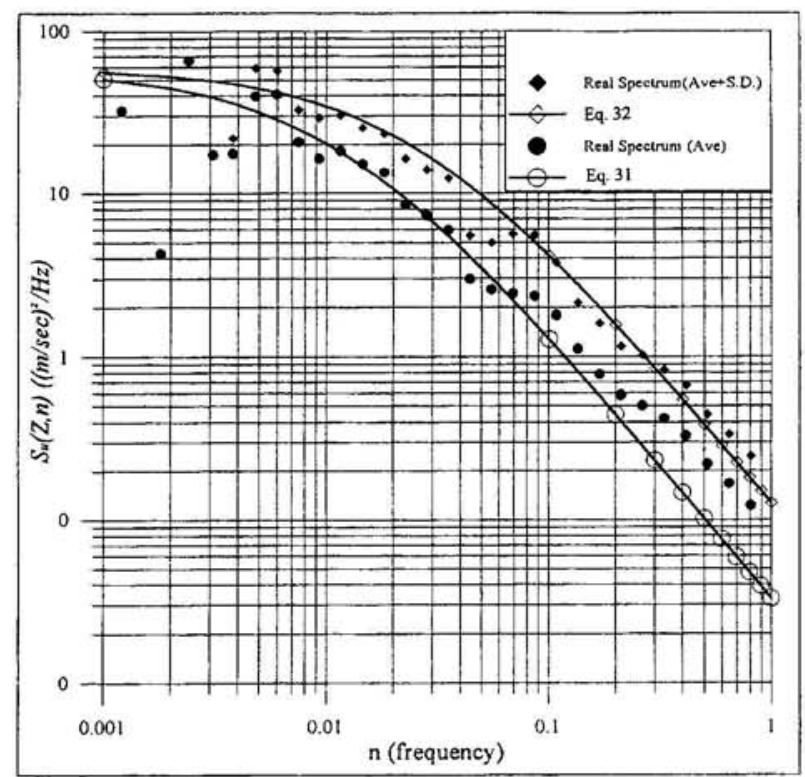

Fig. 1. Proposed Spectrum and Real Spectrum.

speed data recorded by other researchers.

The purpose of the regression of along wind spectra is to establish a energy spectral density function that can be applied for dynamic analysis and structure wind resistant design in Taiwan area. In comparison with several spectrum shown in Fig. 2, we found that the actual wind speed spectra especially for average wind speed plus one standard deviation has a closest match with the formula proposed by Kaimal \& Simiu. The spectrum suggested by Kolmogorov tends to over-estimate as frequency is less than $0.1 \mathrm{~Hz}$, while the one suggested by Davenport tends to underestimate as frequency is less than $0.01 \mathrm{~Hz}$. Therefore, we adopt Kaimal and Simiu's auto-correlation spectrum to proceed regression. The closet match of Kaimal and Simiu's formula by normalized actual spectra of average wind speed plus one standard deviation can also be seen in Fig. 3 and Fig. 4. The Kaimal and Simiu's formula which is a function of the altitude,

$$
\frac{S_{u}(Z, n)}{u_{*}^{2}}=\frac{a f}{n(c+b f)^{5 / 3}} .
$$

where $a, b, c$ : coefficients to be determined.

The least square error method was applied to obtain the spectral density function which is closest to the actual data. There are three variables $a, b$ and $c$ used in this spectral function. First, the variable $\mathrm{c}$ is set to 1.0. Then, the other two variables ( $a$ and $b$ ) can be found under the data of the average wind speed and the data of the average wind speed plus one standard 


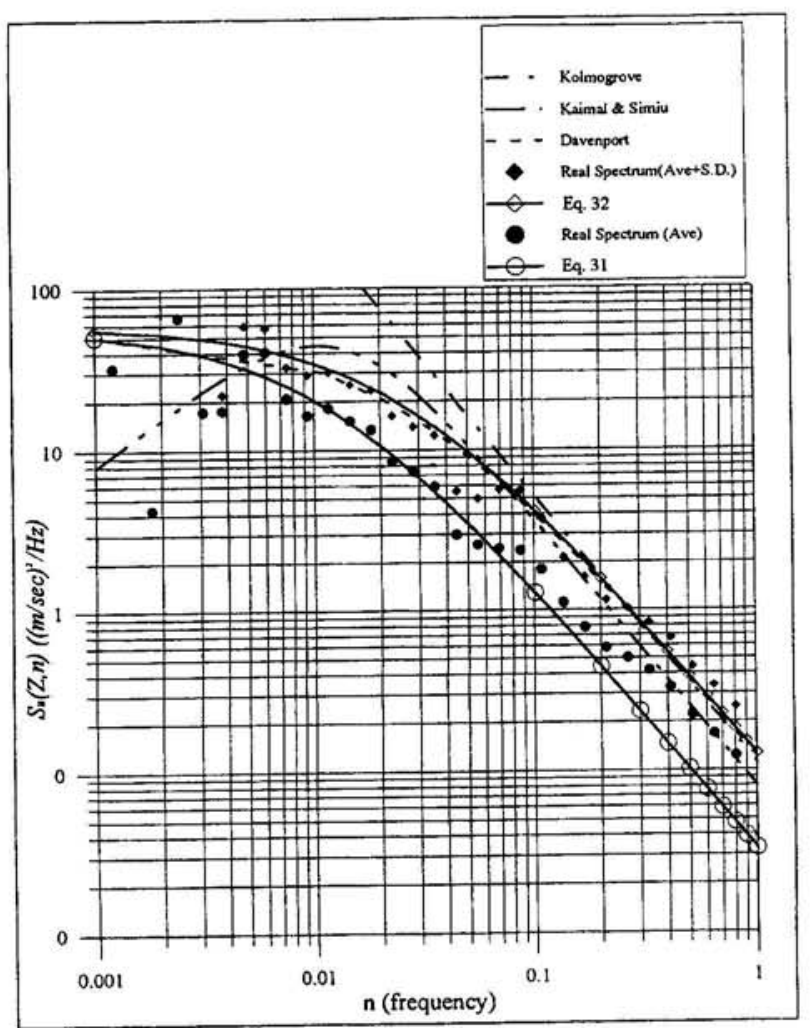

Fig. 2. Different Along Wind Speed Power Spectrum.

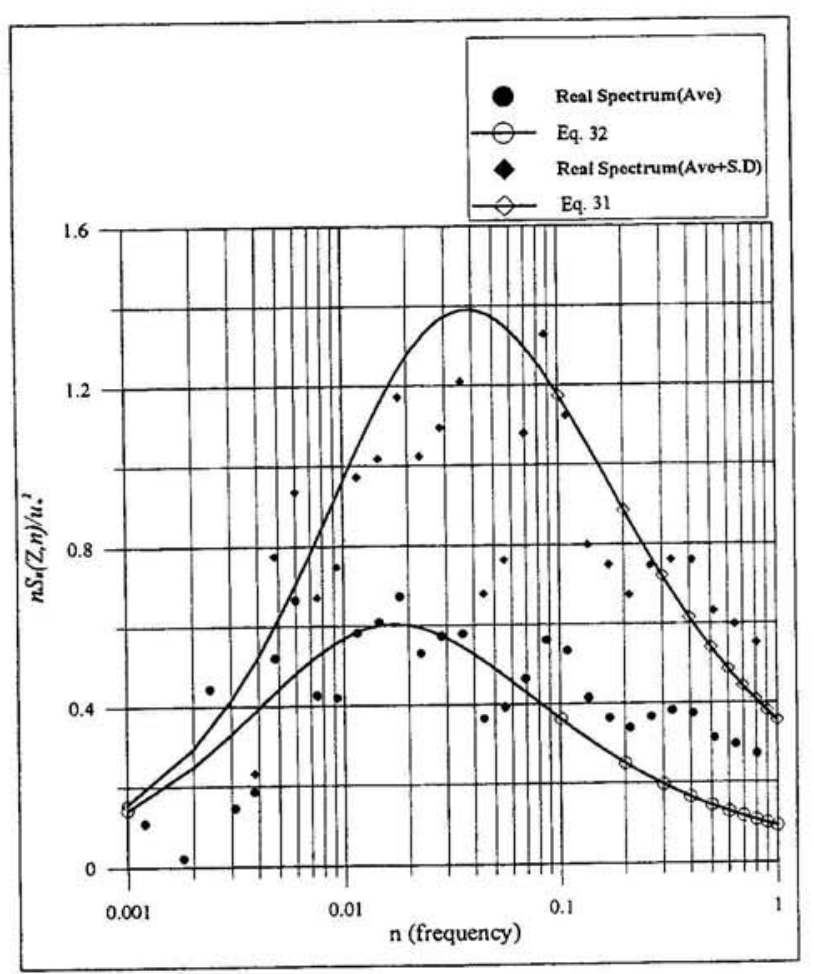

Fig. 3. Normalized Proposed Spectrum and Real Spectrum.

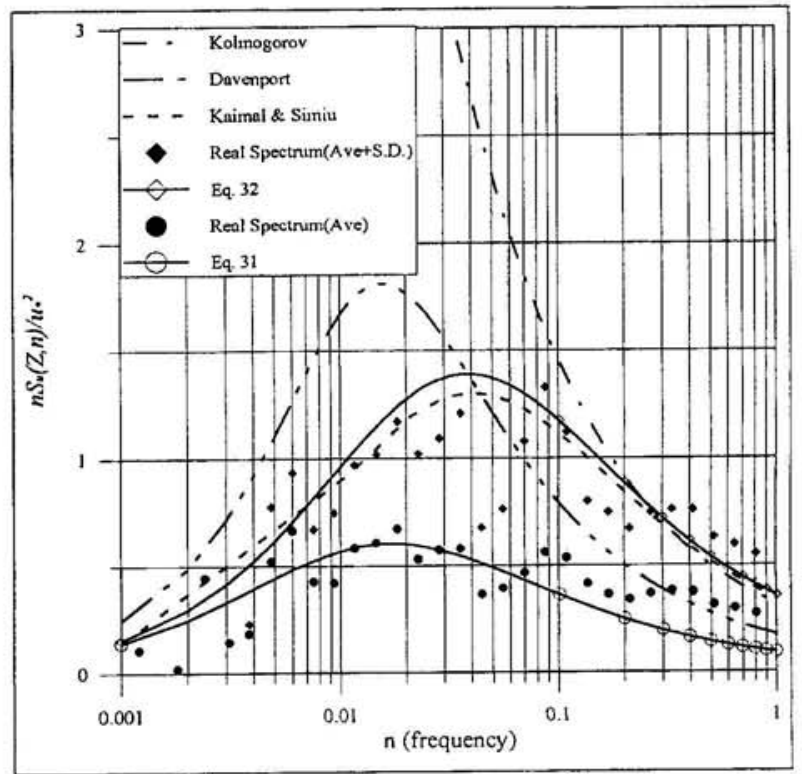

Fig. 4. Normalized Different Along Wind Speed Power Spectrum.

deviation.

By using the average wind speed data, the average wind speed spectra with $a=217$ and $b=118$ is obtained. That is

$$
\frac{n S_{u}(Z, n)}{u_{*}^{2}}=\frac{217 f}{(1+118 f)^{5 / 3}} .
$$

By using the average wind speed plus one standard deviation, the spectra with coefficients $a=222, b=52$ is obtained. That is

$$
\frac{n S_{u}(Z, n)}{u_{*}^{2}}=\frac{222 f}{(1+52 f)^{5 / 3}},
$$

The difference between the above two spectrum and real spectrum obtained from real wind speed data are shown in Fig. 1. It shows lower the frequency higher the spectral energy, especially for frequency range less than $0.01 \mathrm{~Hz}$. Because most tall structures has much higher frequency, therefore, it shall be appropriate to omit the vortex impact and to use quasi-static method to analyze the influence of along wind turbulence on structures.

\section{CONCLUSIONS AND DISCUSSIONS}

1. According to the wind speed spectrum obtained from elapsed wind speed time history data as shown in Fig. 1, the high-energy data are concentratedly distributed in the $0.001 \sim 0.01 \mathrm{~Hz}$ range. Therefore, we suggest that the elapsed time is no less than 1000 seconds when collecting wind speed time history data, otherwise, the obtained spectrum will not be 
accurate. Since the unit time length adopted in this study is 20 minutes for each data, it should still be adequate. However, we recommend that the recorded time per data might extend to 30 minutes for better results.

2. The high-energy area of along wind spectrum is concentratedly distributed between $0.001 \mathrm{~Hz}$ and $0.01 \mathrm{~Hz}$. Generally the dynamic frequency of highrise structures will not be influenced much under external forces with a low vibration frequency. Therefore, it is appropriate to omit the vortex impact effect of along wind force. And we can analyze the along wind force on strictures by Quasi static method.

3. The spectral density function suggested by Kaimal [8] \& Simiu [9] has the closest match with the real spectrum obtained from actual wind speed. Therefore, the along wind speed spectral density function suggested as an design accordance in this study is:

$$
\frac{n S_{u}(Z, n)}{u_{*}^{2}}=\frac{222 f}{(1+52 f)^{5 / 3}} .
$$

4. It is difficult to collect time history data of strong wind speed for an independent researcher without financial sponsor. Therefore, it is strongly recommended that the Central Weather Bureau, which has many anemometers in Taiwan, should collect continuous strong wind speed data (at least $10 \mathrm{~Hz}$ for 30 minutes per unit record) when strong wind (such as typhoon) occurs. After that, the wind speed spectrum analysis in Taiwan area can be improved and enhanced further.

\section{ACKNOWLEDGMENTS}

The authors would like to thank the National Science Council for funding this research (Project No. NSC85-2611-E-019-037).

\section{REFERENCES}

1. Davenport, A.G., "The Spectrum of Horizontal Gushiness near the Ground in High Winds," Journal of the Royal Meteorological Society, Vol. 87, pp. 194-211
(1961).

2. Davenport, A.G., "The Dependence of Wind Load Upon Meteorological Parameters," Proceedings of the International Research Seminar on Wind Effects on Buildings and Structures, Ottawa, Toronto University Press, Toronto, Vol. 1, pp. 19-82 (1968).

3. Solari, G., "Along-Wind Response Estimation: Closed Form Solution," Journal of Structural Engineering, ASCE, Vol. 108, No. 1, pp. 225-244 (1982).

4. Simiu, E. and Scanlan, R.H., "Wind Effects on Structures," 2nd Edition, John Wiley and Sons, Inc., New York, (1986).

5. Von Karman, T., "Progress in the Structural Theory of Turbulence," Proceedings of the National Academy of Science, Washington, D. C., PP. 194-211, (1948).

6. Harris, R.I., "The Nature of Wind, The Modern Design of Wind-Sensitive Structures," Construction Industry Research and Information Association, London, U. K., (1971).

7. Hino, M., "Spectrum of Gusty Wind," Proceedings of the Third International Conference on Wind Effects on Buildings and Structures, Tokyo, Japan, pp. 69-77, (1971).

8. Kaimal, J.C., "Spectral Characteristics of Surface Layer Turbulence," Journal of the Royal Metreorological Soceity, Vol. 98, pp. 563-589 (1972).

9. Simiu, E., "Wind Spectra and Dynamic Along-Wind Response," Journal of the Structural Division, ASCE, Vol. 100, No. 9, pp. 1897-1910 (1974).

10. Teunissen, H.W., "Structure of Mean Winds and Turbulence in the Planetary Boundary Layer over Rural Terrain," Boundary-Layer Meteorology, Vol. 29, pp. 285-312 (1980).

11. Olesen, H.R., Larsen, S.E. and Hojstrup, J., "Modeling Velocity Spectra in the Lower Part of the Planetary Boundary Layer," Boundary-Layer Meteorology, Vol. 29, pp. 285-312 (1984).

12. Solari, G., "Turbulence Modeling for Guest Loading," Journal of Structural Engineering, ASCE, Vol. 113, No. 7, pp. 1550-1569, (1987).

13. Solari, G., "Gust Buffeting I : Peak Wind Velocity and Equivalent Pressure," Journal of Structural Engineering, ASCE, Vol. 119, No. 2, pp. 365-382 (1993). 
臺灣地區順向風風速能量頻譜公式 之探討

張景鐘李育霖

國立台灣海洋大學河海工程學系

摘 要

本文主要是利用歷年來台湀地區賽测之強風 風速歷時資料, 進行頻譜分析, 經由統計迴䠋分析 方法, 探討台管地區合適之順向風風速能量頻譜公 式, 針對結構風壓力設計中有關順向風紊流效應之 風速紊流能量頻譜方程式做深入的探討和分析。在 堂灣地區順向風風速能量頻譜的研究上, 本研究除 了收集分析國內外相關學者所提出之風速能量頻譜

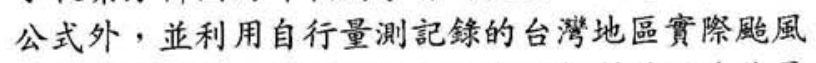
風速歷時資料, 進行頻譜分析與回歸製作風速能量 頻譜; 最後歸纳出一適合台灣地區使用的順向風風 速能量頻譜方程式, 將可以建議提供結構物耐風設 部使用參考。 